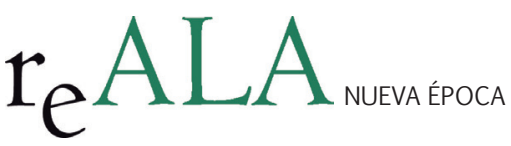

REALA, n Extraordinario, enero 2015 ISSN: 1989-8975

DOI: http://dx.doi.org/10.24965/reala.voiExtra.10219

\title{
Las competencias locales: balance de situación'
}

\author{
Santiago A. Bello Paredes \\ Profesor Titular de Derecho Administrativo. Universidad de Burgos \\ sbello@ubu.es
}

\section{Resumen}

El objeto de este estudio se centra en efectuar una valoración jurídico-administrativa de la situación de las competencias de las entidades locales tras la reforma local aprobada por la Ley estatal de fecha 27 de diciembre de 2013, así como tras las regulaciones realizadas en diversas Comunidades Autónomas. Y la situación resulta especialmente preocupante pues ha supuesto la creación de un ámbito conflictivo entre el Estado y las Comunidades Autónomas, originado por el distinto entendimiento que han efectuado del bloque de constitucionalidad en esta materia.

Palabras clave

Administración local, competencias locales, reforma local.

\section{Local Competences: Balance of Situation}

\section{Abstract}

The purpose of this study focuses on making a legal-administrative assessment of the situation of the competences of local government, after the local government reform adopted by the Law dated December 27, 2013, as well as after reforms adopted in many Autonomous Communities. And the situation is particularly disturbing because has created a conflicting area between the State and the Autonomous Communities, caused by the different understanding that have made about the block of constitutionality in this subject.

\section{Key words}

Local government, local competences, local reform.

1 Este trabajo se enmarca en el proyecto de investigación que lleva por título “Los Enclaves territoriales en España: Balance del estado de la cuestión y formulación de propuestas para su integración en el modelo territorial español” financiado por el Ministerio de Hacienda y Administraciones Públicas y del que es investigador principal Santiago A. Bello Paredes. 


\section{SUMARIO}

1. LA SITUACIÓN COMPETENCIAL EN LA CONSTITUCIÓN ESPAÑOLA. 1.1 La autonomía local en la Constitución. 1.2. El interés local como cláusula constitucional de habilitación competencial.1.2.1. Titularidad de la definición del interés local. 1.2.2. Los distintos supuestos de relaciones entre los respectivos intereses. 2. LAS COMPETENCIAS LOCALES EN EL ÁMBITO ESTATUTARIO. 2.1. El régimen local como competencia estatutaria.2.2. La determinación competencial local en el ámbito estatutario. 3. LAS COMPETENTENCIAS DE LAS ENTIDAES LOCALES TRAS LAS REFORMAS. 3.1. Las competencias locales en la reforma estatal.3.2. Las competencias locales en las reformas autonómicas. 3.3. Los problemas de aplicación del nuevo modelo competencial. 4. CONCLUSIONES. 5. BIBLIOGRAFÍA.

\section{LA SITUACIÓN COMPETENCIAL EN LA CONSTITUCIÓN ESPAÑOLA}

En lo que se refiere a la determinación del ámbito competencial propio de las entidades locales, éste debe ser consecuencia del funcionamiento conjunto de los principios constitucionales de autonomía local e intereses locales, tal y como establece el artículo 137 Constitución Española (CE) cuando procede a determinar el anclaje constitucional de las entidades territoriales². A través del primero, se asegura la existencia de un núcleo esencial y mínimo de competencias salvaguardadas por aplicación del instrumento de la garantía institucional, aunque bien es cierto que este principio constitucional no permite conocer con mayor grado de detalle cuáles son esas competencias locales, ni su contenido concreto 3 .

Y esta regulación jurídica ha supuesto la ruptura con la tradición constitucional española anterior, al elevar la situación de estas entidades públicas a una posición jurídica que nunca antes habían ostentado en nuestro Derecho contemporáneo. En un plano estrictamente normativo se puede afirmar que, en ningún momento, salvo la regulación contenida en los Estatutos municipal y provincial de 1924, se ha asumido en nuestro ordenamiento jurídico la posibilidad de que existiera alguna discrepancia entre la actuación del Estado y las entidades locales, y ello por cuanto éstas han sido siempre configuradas como "eslabones de la misma cadena" (la Administración del Estado) y, por tanto, con la obligación de ejecutar las directrices impuestas por el Gobierno4.

Esta situación cambia radicalmente con la CE en la cual se permite una actuación local basada en el principio de la autonomía local, lo que significa que, del propio entendimiento de la palabra "autonomía" 5 , que esta norma garantiza a las entidades locales una capacidad para autonormarse y autoorganizarse, lo que evidencia que nos encontramos ante ámbitos donde debe existir una amplia facultad de decisión y actuación para este tipo de entidades.

La carencia competencial derivada del principio de autonomía local, antes advertida, debe suplirse a través del principio constitucional del "interés respectivo". Para lograrlo, resulta necesario acudir a la siguiente construcción teorética realizada por nuestro Tribunal Constitucional: el legislador, tanto estatal como autonómico, queda obligado a articular la participación de las entidades locales en la regulación y ejecución de aquellas materias que afecten a sus respectivos intereses, de tal forma que resulta obligatorio que se "dote a cada ente de todas las competencias propias y exclusivas que sean necesarias para satisfacer el interés respectivo" 6 ; lo que supone, en muchas ocasiones, que al no resultar nada sencillo concretar este interés en cada materia, sólo se pueda “distribuir la competencia sobre la misma en función del interés predominante, pero sin que ello justifique un interés exclusivo que justifique una competencia exclusiva en el orden decisorio"7

En esta construcción constitucional, la autonomía local opera como un elemento organizativo, de naturaleza estática si se quiere, de arquitectura de los diversos poderes públicos territoriales, por lo que la determinación concreta de las competencias de las entidades locales no deriva tanto de este principio, sino de la actuación dinámica del principio del interés respectivo. Tal dinamicidad vendrá determinada por el hecho de que el ámbito de actuación de las entidades locales dependerá de las diversas relaciones a las que pueda reconducirse la incidencia de los intereses respectivos de los distintos entes territoriales en cada materia o ámbito funcional específico.

2 Empleando la expresión utilizada por AUTEXIER (1981):581.

3 BELLO PAREDES (2002): 112.

4 BELLO PAREDES (2002): 53. Para ALBI (1966): 40, esta situación ha supuesto que el municipio en España no ha sido más que una modalidad de la administración periférica del Estado, para atender problemas urbanos, dentro de un sistema orgánico subordinado al propio Estado.

ROMANO (1964), ofrece un estudio completo de la evolución del significado de este concepto en el Derecho contemporáneo. STC 4/1981, de 2 de febrero, FJ. 3.

7 Cit. FJ. 3 . 
Por todo ello, y utilizando las palabras del Tribunal Constitucional, "hay que efectuar una redistribución de competencias en función del respectivo interés entre las diversas entidades, para que el modelo de Estado configurado por la Constitución tenga efectividad práctica"”. Y deberán ser las leyes, estatales y autonómicas, los instrumentos a través de los cuales se deban "especificar y graduar las competencias provinciales teniendo en cuenta la relación entre intereses locales y supralocales en los asuntos que conciernen a la comunidad provincial y sin más límite que el reducto indisponible o núcleo esencial de la institución que la Constitución garantiza”.

\subsection{La autonomía local en la Constitución}

A estas alturas de la vigencia de nuestro texto constitucional, no se puede desconocer la importancia que el principio constitucional de Autonomía local tiene en la configuración global de las entidades territoriales locales de nuestro Estado, y así lo asume el texto constitucional en los artículos 137, 140 y 141.

Siguiendo las pautas que ha elaborado nuestro Tribunal Constitucional sobre este principio constitucional, la autonomía local se caracteriza por los siguientes aspectos concretos:

$1^{\circ}$ ) La autonomía es un poder limitado. Y es que, frente al carácter ilimitado y constituyente del principio de la soberanía, la autonomía resulta ser un poder limitado y constituido, ya que "la autonomía no es soberanía” .

De esta forma, deberán ser los legisladores, estatal y autonómicos, quienes determinen el ámbito concreto de actuación de las entidades locales, y ello dependiendo de la diversa valoración y ponderación de los intereses en juego en cada ámbito material. Por tanto, la determinación exacta del ámbito competencial de actuación de las entidades locales corresponderá al legislador ordinario, sin olvidar que existe para las entidades locales un umbral mínimo que les garantiza su participación efectiva en los asuntos que les atañen.

$2^{\circ}$ ) La autonomía local es un derecho de participación de las colectividades que integran las entidades locales en el "gobierno y administración de cuantos asuntos le atañen, graduándose la intensidad de esta participación en función de la relación entre intereses locales y supralocales dentro de tales asuntos o materias" "1. Derecho de participación que podrá contener funciones de naturaleza normativa, de ejecución o de mera participación en la toma de decisiones de otras entidades territoriales de ámbito superior, Estado y Comunidades Autónomas.

$3^{\circ}$ ) La autonomía local resulta preservada como garantía constitucional. Esta característica de contenido negativo o para reaccionar, permite a las entidades locales oponerse a cualquier actuación del legislador que pretenda eliminar el "reducto indisponible o núcleo esencial que la Constitución garantiza" "2 pues esta garantía "no asegura un contenido concreto o un ámbito competencial determinado y fijo de una vez por todas, sino la preservación de una institución en términos recognoscibles para la imagen que de la misma tiene la conciencia social de cada tiempo y lugar"’3. De tal forma que, más allá de este contenido mínimo que protege la garantía institucional, la autonomía local es un concepto jurídico de contenido legal, que permite configuraciones legales diversas, válidas en cuanto respeten aquella garantía institucional. Por tanto, en relación con el juicio de constitucionalidad sólo cabe comprobar si el legislador ha respetado esa garantía institucional.

Además, la determinación del canon de constitucionalidad que permita la protección de la autonomía local debe ceñirse a los preceptos constitucionales (artículos 137, 140 y 141 CE) que establecen ese "contenido mínimo que protege la garantía institucional (...)". También el legislador básico estatal ha de respetar la garantía institucional de la autonomía local puesto que los destinatarios del artículo 137 CE "son todos los poderes públicos, y más concretamente todos los legisladores" ${ }^{14}$. Aunque la legislación básica sobre régimen local no se integra en el "bloque de constitucionalidad", ni constituya canon de validez de otras leyes estatales.

$4^{\circ}$ ) La autonomía local es también resultado de la distribución territorial del poder realizada por la Constitución, lo cual significa que se ha efectuado "una distribución vertical del poder público entre entidades de distinto nivel que son fundamentalmente el Estado, (... ) las Comunidades Autónomas (...) y las provincias y los municipios”'15.

En definitiva, esta elaboración del Tribunal Constitucional puede quedar condensada en la siguiente afirmación,

"la autonomía local reconocida en los artículos 137 y 140 de la Constitución se configura como una garantía institucional con un contenido mínimo que el legislador debe respetar y que se concreta,

8 STC $32 / 1981$, de 28 de julio, FJ. 3.

9 STC 27/1987, de 27 de febrero, FJ.2.

10 Cit., STC 4/1981, FJ. 3.

1 Cit., STC 32/1981, FJ. 4.

12 Cit., STC 32/1981, FJ. 3.

13 Cit., STC 32/1981, FJ. 3.

14 STC 11/1999, de 11 de febrero. FJ. 2.

15 Cit., STC 32/1981, FJ. 3.

REALA, n Extraordinario, enero 2015, ISSN: 1989-8975 - DOI: http://dx.doi.org/10.24965/reala.v0iExtra.10219 
básicamente, en el derecho de la comunidad local a participar a través de órganos propios en el gobierno y administración de cuantos asuntos le atañen, graduándose la intensidad de esta participación en función de la relación existente entre los intereses locales y supralocales dentro de tales asuntos o materias (... ). En la medida en que el constituyente no predeterminó el contenido concreto de la autonomía local, el legislador constitucionalmente habilitado para regular materias de las que sea razonable afirmar que formen parte de ese núcleo indisponible podrá, ciertamente, ejercer en uno u otro sentido su libertad inicial de configuración, pero no podrá hacerlo de manera que establezca un contenido de la autonomía local incompatible con el marco general perfilado en los artículos 137, 140 y 141 CE. So pena de incurrir en inconstitucionalidad por vulneración de la garantía institucional de la autonomía local, el legislador tiene vedada toda regulación de la capacidad decisoria de los entes locales respecto de las materias de su interés que se sitúe por debajo de ese umbral mínimo que les garantiza su participación efectiva en los asuntos que les atañen y, por consiguiente, su existencia como reales instituciones de autogobierno" ${ }^{\prime 16}$.

\subsection{El interés local como cláusula constitucional de habilitación competencial}

\subsubsection{Titularidad de la definición del interés local}

Respecto al interrogante sobre quién debe determinar el interés local, nuestra Constitución guarda silencio sobre la titularidad de esta función "calificadora", no obstante parece que esta titularidad corresponde al legislador sectorial que queda así colocado en una especial situación de preeminencia, concibiendo la Ley como el instrumento fundamental en esta labor de interpretación.

Y así lo ha determinado el Tribunal Constitucional cuando ha establecido que sean los legisladores sectoriales, estatal y autonómicos, quienes determinen y concreten el grado de participación de las entidades locales en cada materia y “en función de los intereses en juego" en cada una de ellas.

No obstante parece evidente que los propios integrantes de la entidad local deben tener, al menos, la posibilidad de determinar qué necesidades sienten como propias y distintas de otras comunidades locales, y ello como consecuencia del ejercicio de su derecho fundamental de participación en la vida pública plasmado en las elecciones democráticas; actuación que deberá ser realizada bien directamente, bien a través de los órganos de participación y gobierno que existan en las entidades locales.

Es esta posibilidad de autodefinición de los intereses locales, como ejercicio por la entidad territorial de la legitimidad democrática que le otorgan las elecciones locales, lo que la doctrina iuspublicista belga"17 ha señalado como "derecho de iniciativa", esto es, la posibilidad de las entidades locales de reconocer sus necesidades e intentarlas cumplir sin esperar otra actuación, normativa o no, de alguna otra entidad política; derecho que que resulta, sin duda, aplicable directamente a nuestro ordenamiento jurídico en virtud del contenido del artículo 4 , apartado $2^{\circ}$, de la Carta Europea de la Autonomía Local (CEAL) ${ }^{18}$, cuando establece el derecho de las entidades locales a "ejercer su iniciativa en toda materia que no esté excluida de su competencia o atribuida a otra autoridad".

Esto es, los términos del “derecho de iniciativa” se potencian sustancialmente con el contenido de la CEAL, pues las actuaciones de las entidades locales serán libres en la determinación de sus necesidades y su consecución, salvo que estas materias "hayan sido excluidas de su competencia o atribuidas a otra autoridad", pero no por la libre voluntad del legislador, sino siempre que ésta, por su amplitud, naturaleza o por las necesidades de eficacia o economía, no pueda ser ejercida por la Entidad local, artículo 4.3 CEAL.

Por tanto, se deduce que el titular del derecho de definición del contenido y extensión de los "intereses locales" reside tanto en la propia entidad local, a través de su derecho de iniciativa, como en el legislador nacional y autonómico en su actuación sobre los distintos sectores de acción pública al determinar los intereses respectivos de cada una de ellas.

El problema se plantea cuando la determinación o evaluación de los "respectivos intereses" realizada por los órganos de las entidades locales no coincide, o se contrapone, con la realizada posteriormente por el legislador.

Así las cosas, si todo el sistema de la habilitación constitucional de las entidades locales depende de la determinación de los diversos intereses respectivos en cada materia (artículos 137, 140 y 141 CE), para poder construir no sólo un parámetro de constitucionalidad de la norma jurídica, sea estatal o autonómica, que los defina y regule, sino también un instrumento para la previa determinación de las funciones normativas entre

\footnotetext{
16 STC 95/2014, de 12 de junio, FJ. 5.

17 DELPÉRÉE (1981): 177.

18 BOE n 47, de 24 de febrero de 1989, y ratificada por España en fecha 20 de enero de 1988.
} 
todas las entidades territoriales, nos vemos en la obligación de determinar las distintas relaciones en que pueden encontrarse estos intereses respectivos.

Y en este sentido se expresa el Tribunal Constitucional cuando concluye que en el sistema constitucional establecido en los artículos 137, 140 y 141 al no predeterminarse:

“El contenido concreto de la autonomía local, el legislador constitucionalmente habilitado para regular materias de las que sea razonable afirmar que formen parte de ese núcleo indisponible podrá, ciertamente, ejercer en uno u otro sentido su libertad inicial de configuración, pero no podrá hacerlo de manera que establezca un contenido de la autonomía local incompatible con el marco general perfilado en los artículos 137, 140 y 141 CE”'19.

\subsubsection{Los distintos supuestos de relaciones entre los respectivos intereses}

No siempre los intereses locales, autonómicos o estatales se van a encontrar en una relación de exclusión o de oposición total, sino que, muy al contrario, en la generalidad de las ocasiones van a situarse en una relación de colaboración para la regulación de las materias y la mejor satisfacción de las aspiraciones de los ciudadanos.

De ahí que se pretenda resaltar la siguiente tipología, al menos: complementariedad, suplementariedad, y exclusión ${ }^{20}$.

La relación de complementariedad, entre los diversos intereses respectivos, se puede definir como aquella situación en la que el interés público estatal se ve satisfecho completamente con la regulación de los principios fundamentales de una materia, dejando el resto de esta actuación para la satisfacción de los intereses autonómicos o locales en la regulación que de cada uno de ellos se haga por cada entidad territorial.

De esta forma, el interés público en esa materia no puede ser definido de forma completa y unilateral por alguna de las entidades territoriales, sino que es el sumatorio de varios intereses diversos; por tanto, el interés nacional no cubre la totalidad de la materia, sino que en ella confluyen además, intereses autonómicos, o/y, intereses locales.

La relación de suplementariedad puede ser definida como aquélla en la que el interés público sólo se ve cumplido si cubre la totalidad de la materia en la que se evidencia su existencia. En términos normativos, la actuación estatal, y referida al cumplimiento de los intereses generales, hace relación a la determinación de un régimen jurídico uniforme e idéntico en la totalidad del territorio nacional fijando "un mínimo común denominador" sobre la materia regulada.

La diferencia fundamental, con el tipo de relación anterior, se evidencia en cuanto que en la relación de suplementariedad se deduce una regulación normativa en sí sola suficiente y autónoma, mientras que en la de complementariedad no es suficiente, sino que necesita su desarrollo por la normativa autonómica o local.

Por último, en la relación de exclusión el interés público queda cumplido con una actuación del Estado, de las Comunidades Autónomas o de las entidades locales determinando y regulando sus "respectivos intereses", y que el resto de entes públicos territoriales no puede modificar dado que no existe ningún otro interés público que se deduzca de esa materia.

\section{LAS COMPETENCIAS LOCALES EN EL ÁMBITO ESTATUTARIO}

\subsection{El régimen local como competencia estatutaria}

El presente apartado tiene como finalidad fundamental efectuar una valoración de la situación jurídica en la que se encuentran las entidades locales en el marco regulatorio de los nuevos Estatutos de Autonomía reformados a partir de la VIII Legislatura de las Cortes Generales (años 2004 a 2008) y hasta la actualidad.

De esta forma, se han aprobado las siguientes reformas estatutarias: Ley Orgánica 1/2006, de 10 de abril, de reforma de la Ley Orgánica 5/1982, de 1 de julio, de Estatuto de Autonomía de la Comunidad Valenciana (EACV); Ley Orgánica 6/2006, de 19 de julio, de reforma del Estatuto de Autonomía de Cataluña (EAC); Ley Orgánica 1/2007, de 28 de febrero, de reforma del Estatuto de Autonomía de las Illes Balears (EAIB); Ley Orgánica 2/2007, de 19 de marzo, de reforma del Estatuto de Autonomía de Andalucía (EAA); Ley Orgánica 5/2007, de 20 de abril, de reforma del Estatuto de Autonomía de Aragón (EAAR); Ley Orgánica 14/2007, de 30 de noviembre, de reforma del Estatuto de Autonomía de Castilla y León (EACyL); Ley Orgánica 1/2011, de 28 de enero, de reforma del Estatuto

19 STC 159/2001, de 5 de julio, FJ.4.

20 BELLO PAREDES (2002): 146.

REALA, n Extraordinario, enero 2015, ISSN: 1989-8975 - DOI: http://dx.doi.org/10.24965/reala.v0iExtra.10219 
de Autonomía de la Comunidad Autónoma de Extremadura (EAE); Ley Orgánica 7/2013, de 28 de noviembre, de reforma de la Ley Orgánica 4/1982, de 9 de junio, de Estatuto de Autonomía de la Región de Murcia (EARM) y, por último, la Ley Orgánica 2/2014, de 21 de mayo, de reforma del Estatuto de Autonomía de Castilla-La Mancha (EACM).

Y hemos de partir de una primera afirmación, cuál es la de señalar que la materia o competencia sobre el régimen local tiene una referencia expresa en los diversos Estatutos de Autonomía, y ello derivado de la distribución competencial realizada, entre el Estado y las Comunidades Autónomas, a partir del contenido de la CE; máxime cuando ha existido un movimiento de "interiorización" de la regulación de la instancia local por parte de varias Comunidades Autónomas, y confesadamente por la de Cataluña²1.

En este sentido, la Jurisprudencia del Tribunal Constitucional ha sancionado una distribución de competencias del siguiente tenor:

"Con carácter general y para todo tipo de materias, el que fije unos principios o bases relativos a los aspectos institucionales (organizativos y funcionales) y a las competencias locales, encontrando cobertura a esa encomienda estatal en el concepto mismo de «bases del régimen jurídico de las Administraciones Públicas», por cuanto dicha expresión engloba a las Administraciones locales"22.

Afirmando posteriormente que, "difícilmente puede afirmarse el fin del carácter bifronte del régimen local. Este carácter es el resultado «de la actividad concurrente del Estado (...) y de las Comunidades Autónomas» (STC 84/1982, de 23 de diciembre, FJ. 4), de modo que «junto a una relación directa Estado-Corporaciones locales, existe también una relación, incluso más natural e intensa, entre éstas y las propias Comunidades Autónomas» (STC 331/1993, de 12 de noviembre, FJ. 3). Y aquella concurrencia, como no podría ser de otra manera, ineludiblemente pervive en cuanto el ejercicio de las competencias autonómicas en materia de régimen local ha de ajustarse, necesariamente, a la competencia que sobre las bases de la misma corresponde al Estado ex artículo 149.1.18 CE, por lo que la regulación estatutaria ha de entenderse, en principio, sin perjuicio de las relaciones que el Estado puede legítimamente establecer con todos los entes locales"23.

En conclusión, nos encontramos ante una materia o competencia de regulación "bifronte”, de ahí la necesidad de su estudio y valoración jurídica en el ámbito estatutario autonómico.

Esta asunción competencial se ve expresamente reflejada en los Estatutos Autonomía reformados. Unos con mayor grado de detalle, EAC y EAA (artículos 160 y 60, respectivamente) y el resto con un grado de concreción menor, quedando reducida a la mínima expresión en el EACV, EAE, EACM y en el EACyL, cuando éste último establece como competencia compartida, de desarrollo normativo y ejecución, la competencia sobre régimen local, artículo $71.11^{\circ}$.

En un sentido diametralmente opuesto por su extensión, el artículo 160.1 EAC establece que:

"Corresponde a la Generalitat la competencia exclusiva en materia de régimen local que, respetando el principio de autonomía local, incluye: a) Las relaciones entre las instituciones de la Generalitat y los entes locales, así como las técnicas de organización y de relación para la cooperación y la colaboración entre los entes locales y entre éstos y la Administración de la Generalitat, incluyendo las distintas formas asociativas, mancomunadas, convencionales y consorciales. b) La determinación de las competencias y de las potestades propias de los municipios y de los demás entes locales, en los ámbitos especificados por el artículo 84. (...)”.

No resulta, por tanto, una cuestión baladí la necesaria existencia de una referencia expresa a la materia del régimen local en los diversos Estatutos de Autonomía, pues supone la plasmación al máximo nivel autonómico la asunción competencial del régimen jurídico local, con un mayor o menor grado de autonomismo local, pero siempre respetando la competencia del legislador estatal para definir las bases del régimen local en toda su extensión ${ }^{24}$.

21 PAREJO (2009): 20.

22 STC 214/1989, de 21 de diciembre, FJ. 3.

23 STC 31/2010, de 28 de junio, FJ. 36.

24 PAREJO (2009): 38. 


\subsection{La determinación competencial local en el ámbito estatutario}

En el EAC, además de la asunción expresa de la competencia sobre régimen local, se produce una detallada y extensa relación de las materias sobre las que pueden actuar los municipios. Así en este Estatuto se establece el derecho de los municipios a tener "un núcleo de competencias propias que deben ser ejercidas por dichas entidades con plena autonomía, sujeta sólo a control de constitucionalidad y de legalidad”, artículo 84.1. Igualmente, se procede a realizar una enumeración detallada de los ámbitos competenciales, que no de las competencias y funciones propias, donde pueden actuar los municipios; así, su artículo $84.2^{25}$ señala que:

"Los gobiernos locales de Cataluña tienen en todo caso competencias propias sobre las siguientes materias en los términos que determinen las leyes ${ }^{26}$ :

a) La ordenación y la gestión del territorio, el urbanismo y la disciplina urbanística y la conservación y el mantenimiento de los bienes de dominio público local.

b) La planificación, la programación y la gestión de vivienda pública y la participación en la planificación en suelo municipal de la vivienda de protección oficial.

c) La ordenación y la prestación de servicios básicos a la comunidad.

d) La regulación y la gestión de los equipamientos municipales.

e) La regulación de las condiciones de seguridad en las actividades organizadas en espacios públicos y en los locales de concurrencia pública. La coordinación mediante la Junta de Seguridad de los distintos cuerpos y fuerzas presentes en el municipio.

f) La protección civil y la prevención de incendios.

g) La planificación, la ordenación y la gestión de la educación infantil y la participación en el proceso de matriculación en los centros públicos y concertados del término municipal, el mantenimiento y el aprovechamiento, fuera del horario escolar, de los centros públicos y el calendario escolar.

h) La circulación y los servicios de movilidad y la gestión del transporte de viajeros municipal.

i) La regulación del establecimiento de autorizaciones y promociones de todo tipo de actividades económicas, especialmente las de carácter comercial, artesanal y turístico y fomento de la ocupación.

j) La formulación y la gestión de políticas para la protección del medio ambiente y el desarrollo sostenible.

k) La regulación y la gestión de los equipamientos deportivos y de ocio y promoción de actividades.

I) La regulación del establecimiento de infraestructuras de telecomunicaciones y prestación de servicios de telecomunicaciones.

m) La regulación y la prestación de los servicios de atención a las personas, de los servicios sociales públicos de asistencia primaria y fomento de las políticas de acogida de los inmigrantes.

25 Precepto que fue declarado constitucional por la STC 31/2010, cit., FJ. 37. Aunque en su FJ. 100 precisa que “la competencia de la Generalitat para asignar competencias a los gobiernos locales se circunscribe a las materias en las que el Estatuto atribuye competencias a la Comunidad Autónoma (...), y, por tanto, respetar las competencias del Estado".

26 En un sentido similar el artículo 92.2 EAA. 
n) La regulación, la gestión y la vigilancia de las actividades y los usos que se llevan a cabo en las playas, los ríos, los lagos y la montaña".

Estableciendo como principios delimitadores de estas competencias los referidos a la subsidiariedad y a la suficiencia financiera, artículo 84.3 EAC.

Otros Estatutos de autonomía, por el contrario, no recogen ningún precepto que establezca un listado de materias que prefiguren la competencia de las entidades locales, sino que se limitan a establecer que los municipios y provincias tendrán aquellas competencias "que se establecen en la legislación básica del Estado y de la Comunidad Autónoma”, artículos 45.1 y 47.1 EACYL. Esta solución también ha sido la elegida por los Estatutos de Valencia, Aragón y Extremadura.

De estas referencias estatutarias puede efectuarse una misma crítica de técnica jurídica, pues ninguna de ellas desciende a la concreción detallada del ámbito competencial de las entidades locales, ni por supuesto contienen una enumeración de sus competencias propias, sino que se limitan a enunciar diversas materias sobre las que podrán actuar las entidades locales, “en los términos que determinen las leyes”. Esta técnica normativa, fuente de una importante inseguridad jurídica en el plano competencial, es similar a la utilizada por el legislador estatal en la redacción del artículo 25.2 LRBRL.

Como nota diferencial, el Estatuto de las Illes Balears sí establece un listado exhaustivo de las competencias propias de los Consejos Insulares, que no así de los municipios, al remitirse para éstos a la legislación básica del Estado y al legislador sectorial.

Además, estatutariamente se regula la posibilidad de efectuar transferencias y delegaciones de competencias, artículo 93.1 EAA, artículo 64.2 EAV, artículo 75 EAIB para los municipios y artículo 50 EACyL. Siendo de destacar, en este ámbito competencial, que sólo el EACyL reconoce de forma expresa el derecho de iniciativa a los municipios, y ello al establecer en su artículo 45.3 que, "Ios municipios tienen capacidad para ejercer su iniciativa en toda materia de interés local que no esté expresamente excluida de su competencia o atribuida a otras Administraciones por la legislación del Estado o de la Comunidad Autónoma".

\section{LAS COMPETENCIAS DE LAS ENTIDAES LOCALES TRAS LAS REFORMAS}

\subsection{Las competencias locales en la reforma estatal}

La entrada en vigor el día 31 de diciembre de 2013 de la Ley 27/2013, de 27 de diciembre, de racionalización y sostenibilidad de la Administración Local (LRSAL) ${ }^{27}$, de la que debe destacarse entre sus objetivos básicos, según se recoge en su Preámbulo, el de "clarificar las competencias municipales para evitar duplicidades con las competencias de otras Administraciones, de forma que se haga efectivo el principio "una Administración una competencia”, ha pretendido suponer una modificación sustancial del sistema competencial existente en el ámbito local, entre otras razones, al dejar sin contenido el artículo 28 de la $\mathrm{LRBRL}^{28}$, que posibilitaba a las entidades locales la realización de actividades complementarias prácticamente sobre cualquier materia y pretender diseñar un nuevo sistema competencial tendente a evitar los posibles solapamientos y situaciones de concurrencia competencial entre varias Administraciones Públicas.

Además, se ha pretendido evitar que esta complejidad competencial incida negativamente en la hacienda local ${ }^{29}$, para lo cual, se persigue evitar la duplicidad en la prestación de servicios o la prestación de éstos sin un título competencial específico habilitante y sin contar con los recursos adecuados para ello, velando por la sujeción de dicho régimen competencial a los requerimientos legales derivados de los principios de estabilidad presupuestaria y sostenibilidad financiera, consecuencia obligada tras la reforma del artículo 135 de la CE y su desarrollo a través de la Ley Orgánica 2/2012, de 27 de abril, de estabilidad presupuestaria y sostenibilidad financiera (LOEPSF) ${ }^{30}$.

27 Norma que ha sido recurrida ante el Tribunal Constitucional por los Gobiernos Autonómicos de Andalucía, Canarias, Cataluña, Principado de Asturias, por los Parlamentos Autonómicos de Andalucía, Extremadura, Cataluña, Navarra, por diversos Grupos Parlamentarios del Congreso de los Diputados y, por último, se ha planteado un Conflicto en defensa de la autonomía local por varios miles de municipios españoles.

28 Al establecer su artículo primero, apartado once, que "se suprime el contenido del artículo 28" de la LRBRL, el cual establecía que "Ios municipios pueden realizar actividades complementarias de las propias de otras Administraciones Públicas y, en particular, las relativas a la educación, la cultura, la promoción de la mujer, la vivienda, la sanidad y la protección del medio ambiente".

29 Afirmando en este Preámbulo que, "en un momento en el que el cumplimiento de los compromisos europeos sobre consolidación fiscal son de máxima prioridad, la Administración local también debe contribuir a este objetivo racionalizando su estructura, en algunas ocasiones sobredimensionada, y garantizando su sostenibilidad financiera".

30 En este sentido también se pronuncian NAVARRO y ZAFRA (2014): 2, para quienes la LRSAL no es consecuencia tanto de la evaluación negativa del funcionamiento de la Administración local, sino la necesidad de poner en marcha el programa de reformas de la Administración española que viene impuesto por los compromisos contraídos con Europa y plasmados en la reforma de la CE, artículo 135. 
$Y$ en este sentido debe resaltarse la importancia adquirida por estos principios constitucionales que se alzan como un nuevo "canon de constitucionalidad" que se debe imponer a todos los poderes públicos, tal y como resalta el Tribunal Constitucional en su sentencia de fecha 18 de octubre de $2011^{31}$.

Para ello, tal y como expresa el Preámbulo de la LRSAL, la metodología que se emplea para realizar esta reforma se centra en la realización de "un listado de materias en que los municipios han de ejercer, en todo caso, competencias propias, estableciéndose una reserva formal de ley para su determinación, así como una serie de garantías para su concreción y ejercicio"; pues el legislador de la LRSAL entiende que "las entidades locales no deben volver a asumir competencias que no les atribuye la ley y para las que no cuenten con la financiación adecuada" y, además, concluye afirmando que "por tanto, solo podrán ejercer competencias distintas de las propias o de las atribuidas por delegación cuando no se ponga en riesgo la sostenibilidad financiera del conjunto de la Hacienda municipal, y no se incurra en un supuesto de ejecución simultánea del mismo servicio público con otra Administración Pública".

A la vista de esta declaración de intenciones, la LRSAL procede a dar una nueva redacción al artículo 25 LRBRL, aunque sin solucionar los problemas de redacción que padecía este precepto desde su redacción originaria, y referidos fundamentalmente a su ausencia de concreción de las competencias municipales ${ }^{32}$. De esta forma, se sigue estableciendo un listado sobre "materias" en las que deben actuar los municipios con un carácter amplio e indeterminado; máxime cuando el apartado $1^{\circ}$ sigue estableciendo que:

"El Municipio, para la gestión de sus intereses y en el ámbito de sus competencias, puede promover actividades y prestar los servicios públicos que contribuyan a satisfacer las necesidades y aspiraciones de la comunidad vecinal en los términos previstos en este artículo".

La modificación de la LRBRL, a través de la LRSAL, ha tratado de frenar la "vis expansiva" de los municipios asumiendo competencias al añadir que esta acción se realizará "en los términos previstos en este artículo". Y entre cuyos condicionantes se encuentra el contenido en el apartado $4^{\circ}$ de este precepto, en el cual se exige que la ley que habilite la competencia local debe contener:

"Una memoria económica que refleje el impacto sobre los recursos financieros de las Administraciones Públicas afectadas y el cumplimiento de los principios de estabilidad, sostenibilidad financiera y eficiencia del servicio o la actividad".

Y todo ello, en el entorno de que el ámbito de las competencias municipales se determinará "por Ley (...) conforme a los principios de descentralización, eficiencia, estabilidad y sostenibilidad financiera", nueva redacción del artículo 25.3 LRBRL. Pues ya en el artículo 2.1 LRBRL esta reforma incluye la afirmación de que el ámbito competencial de las entidades locales debe garantizar los principios de "eficacia y eficiencia y con estricta sujeción a la normativa de estabilidad presupuestaria y sostenibilidad financiera". Hasta el punto de que las entidades locales sólo podrán ejercer otras competencias que no sean las propias, y las atribuidas por delegación,

"cuando no se ponga en riesgo la sostenibilidad financiera del conjunto de la Hacienda municipal, de acuerdo con los requerimientos de la legislación de estabilidad presupuestaria y sostenibilidad financiera y no incurra en un supuesto de ejecución simultánea del mismo servicio público con otra Administración Pública (...)”, nueva redacción del artículo 7.4 LRBRL.

Además, y en plena coherencia con lo declarado en su Preámbulo, el apartado $5^{\circ}$ establece la necesidad de que esta ley de habilitación debe garantizar "que no se produce una atribución de la misma competencia a otra Administración Pública".

De una comparación del listado incluido en el artículo 25.2 LRBRL, antes y después de la LRSAL, parece evidente que se ha producido la supresión en materias tales como la seguridad en lugares públicos, la promoción y gestión de vivienda (pues ahora sólo existe una referencia a esta actividad en la vivienda de protección pública y con

31 STC 157/2011, de 18 de octubre, FJ. 3, al afirmar que el principio de estabilidad presupuestaria consagrado en el artículo 135 CE contiene "un mandato constitucional que, como tal, vincula a todos los poderes públicos y que por tanto, en su sentido principal, queda fuera de la disponibilidad -de la competencia- del Estado y de las Comunidades Autónomas".

32 Pues en éste, desde su redacción inicial, no se determina con precisión las competencias municipales, sino que enumera un conjunto de materias en las que el legislador sectorial, estatal y autonómico, debe posteriormente proceder a identificar las competencias locales, artículo 25.2 LRBRL. Y esta defectuosa técnica legislativa se reitera en la reforma de la LRSAL, lo que hace dudar a RIVERO YSERN (2014): 27 de que realmente se haya realizado realmente una reforma, sino que se ha producido una reafirmación del sistema anterior, con la inclusión exclusivamente del respeto a los principios de estabilidad presupuestaria y sostenibilidad financiera. 
criterios de sostenibilidad financiera), la sanidad y educación (salvo las funciones encomendadas en el apartado n), la defensa de los consumidores y usuarios, la participación en la gestión de la atención primaria de salud y la prestación de los servicios sociales y de promoción y reinserción social.

De este listado de materias, resalta33 la supresión de las cuestiones relativas a los servicios sociales ${ }^{34}$, pues los Ayuntamientos se han mostrado como instrumentos eficaces en esta acción pública tan necesaria en estos tiempos de crisis económica, y ello por su cercanía a las personas y colectivos englobados en esta situación.

Debe entenderse que esta supresión ${ }^{35}$ obedece a criterios referidos a la hacienda local, que no a la inexistencia de intereses locales, y ello pese a que no exista referencia alguna sobre esta cuestión salvo en la Disposición adicional $15^{\text {a }}$ (educación) y en las Disposiciones transitorias $1^{\text {a }}$ (salud), $2^{\text {a }}$ (servicios sociales) y $3^{\text {a }}$ (inspección sanitaria), a través de las cuales se pretende excluir del ámbito municipal el ejercicio de competencias en estas materias y ubicarlas en el ámbito autonómico. Dicho de otra forma, la supresión de las materias sobre las cuales el legislador sectorial había habilitado competencialmente a los municipios, no queda justificada por la LRSAL si obedece a criterios propios de la Hacienda local o derivados de la configuración del régimen local.

En definitiva, y ésta es la posible primera quiebra de la reforma, en la LRSAL el legislador estatal ejerce competencias estatales sobre la materia de "régimen local", contenidas en el artículo 149.1.18 CE, y sobre la "hacienda general", contenidas en el artículo 149.1.14a , que pueden suponer una invasión competencial de las competencias autonómicas.

En virtud del primero de estos títulos competenciales, según el Tribunal Constitucional se permite "al legislador estatal fijar «unos principios o bases relativos a los aspectos institucionales (organizativos y funcionales) y a las competencias locales» de los entes locales constitucionalmente necesarios"36, para lo cual efectúa un determinado entendimiento (interpretación) del bloque de la constitucionalidad que puede afectar a competencias que según este mismo bloque pueden pertenecer a las Comunidades Autónomas. Y ello pese al carácter bifronte que la regulación del régimen local tiene en la Jurisprudencia constitucional, tal y como ya hemos estudiado anteriormente.

En este sentido debe recordarse la sentencia del Tribunal Constitucional de 21 de diciembre de 1989, cuando formula una interpretación constitucional del artículo 2.2 LRBRL, al considerar que "las leyes básicas deberán decir qué competencias corresponden en una materia compartida a las entidades locales por ser ello necesario para garantizarles su autonomía (artículos 137 y 140 de la Constitución)”, pero sigue manifestando que:

"ello no asegura que la ley básica estatal y sectorial (montes, sanidad, etc.) que tal cosa disponga sea, sin más, constitucional porque si excede de lo necesario para garantizar la institución de la autonomía local habrá invadido competencias comunitarias y será por ello inconstitucional, correspondiendo en último término a este Tribunal Constitucional ponderar, en cada caso, si las competencias de ejecución atribuidas a los entes locales son o no necesarias para asegurar su autonomía”37.

De esta forma, la LRSAL para salvar esta posible tacha de inconstitucionalidad debe haberse adecuado a fijar "unos principios o bases relativas a las competencias locales", efectuando un entendimiento del bloque de constitucionalidad del reparto competencial entre el Estado y las Comunidades Autónomas para garantizar la autonomía de las entidades locales.

Por otra parte, en relación al título competencial contenido en el artículo 149.1.14a, "Hacienda general y Deuda del Estado", se permite al Estado regular con carácter exclusivo tal materia en aquellos casos en los que la normativa estatal tenga por objeto "la salvaguarda de la suficiencia financiera de las Haciendas locales garantizada por el artículo $142 \mathrm{CE}$, en cuanto presupuesto indispensable para el ejercicio de la autonomía local constitucionalmente reconocido en los artículos 137, 140 y 141 CE"38.

33 También llama la atención de la materia de "consumidores y usuarios" que los municipios han ejercido e a través de las OMIC (Oficinas Municipales de Información al Consumidor), elaborando un extenso tejido de protección a los consumidores y, en muchas ocasiones, de forma coordinada con la implantación de órganos de mediación entre éstos y los empresarios.

34 Que ahora se contienen únicamente en el apartado e) que se refiere a la "evaluación e información de situaciones de necesidad social y la atención inmediata a personas en situación o riesgo de exclusión social”.

35 Situación que VELASCO CABALLERO (2014): 6 interpreta en el sentido de que tal supresión no conduce a una disminución de las competencias municipales, por entender que "los municipios seguirán siendo titulares de las competencias que actualmente les atribuyen las leyes sectoriales del Estado o las leyes de régimen local y las leyes sectoriales de las comunidades autónomas”.

36 STC 214/1989, de 21 de diciembre, FJ. 1 y 4.

37 Cit. FJ. 4. El artículo 2.2 LRBRL establece que "las leyes básicas del Estado previstas constitucionalmente deberán determinar las competencias que ellas mismas atribuyan o que, en todo caso, deban corresponder a los entes locales en la materia que regulen".

38 STC 233/1999, de 16 de diciembre, FJ.4. 
Por otra parte, en relación al conjunto de servicios públicos ${ }^{39}$ mínimos y obligatorios que establece para los municipios el artículo 26 LRBRL, éstos se centran en los municipios por tramos de población de más de 5.000 habitantes, de más de 20.000 habitantes y de más de 50.000 habitantes. La reforma de la LRBRL consagra la coordinación de la prestación de estos servicios por parte de la Diputación provincial a los municipios de población inferior a los 20.000 habitantes y referidos a los servicios de "recogida de residuos, limpieza viaria, abastecimiento domiciliario de agua potable, acceso a los núcleos de población, pavimentación de las vías y tratamiento de residuos", nueva redacción del artículo 26.2 LRBRL.

Pues la coordinación tendrá por objeto "asegurar el cumplimiento de la legislación de estabilidad presupuestaria y sostenibilidad financiera”, nueva redacción del artículo 10.3 LRBRL.

En relación con esta nueva competencia provincial, debe reseñarse la jurisprudencia elaborada por el Tribunal Constitucional ${ }^{40}$ en relación con la determinación de las nuevas competencias provinciales contenida en la reforma del régimen local realizada a través de la Ley estatal 57/2003, de 16 de diciembre, y en la cual se estableció como nueva competencia provincial la "prestación de servicios públicos de carácter supramunicipal, y en su caso, supracomarcal”, reforma cuya constitucionalidad ha sido avalada al entender que:

“La atribución de una nueva competencia obedece al reforzamiento del papel de las entidades provinciales que persigue la Ley de medidas para la modernización del gobierno local y de ahí su necesidad para la definición del modelo de autonomía provincial, modelo que, en contra de lo que afirma el recurrente, no queda limitado única y exclusivamente al desarrollo del contenido esencial de la garantía institucional que comprende la función de cooperación económica a la realización de obras y servicios municipales, o el apoyo a los municipios, según afirmamos en la STC 109/1998, de 21 de julio, sino que se extiende a aquello que resulte necesario para la definición del modelo común de autonomía provincial, con independencia del posterior desarrollo normativo de las bases que en todo caso corresponde a las Comunidades Autónomas"41.

Esta doctrina jurisprudencial puede avalar la reforma contenida en la LRSAL para las provincias, salvo que se considere que ésta menoscaba la garantía constitucional de la autonomía de los municipios.

Actividad de coordinación que abarcará proponer la selección de la "forma de prestación", la cual deberá se consensuada con los municipios, y que será acordada por el Ministerio de Hacienda y Administraciones Públicas, nueva redacción del artículo 26.2 LRBRL. Para lo cual, el eje central de esta decisión descansará en la evaluación del "coste efectivo" del servicio, nuevo artículo 116 ter LRBRL.

Este papel de las Diputaciones provinciales como entes coordinadores de las competencias municipales mínimas obligatorias, queda resaltado en la nueva redacción del artículo 36.1 a) y h) LRBRL, pues en éste último se afirma como competencia propia de éstas:

"El seguimiento de los costes efectivos de los servicios prestados por los municipios de su provincia. Cuando la Diputación detecte que estos costes son superiores a los de los servicios coordinados o prestados por ella, ofrecerá a los municipios su colaboración para una gestión coordinada más eficiente de los servicios que permita reducir estos costes".

La nueva redacción del art. 36.1.a) de la LRBRL atribuye con carácter general, en todo caso, como competencia propia de las Diputaciones Provinciales, la coordinación de los servicios municipales entre sí, con la finalidad de "asegurar la prestación integral y adecuada en la totalidad del territorio provincial de los servicios de competencia municipal”, artículo 31.2.a) LRBRL.

La formulación de esta competencia propia de coordinación de las Diputaciones provinciales, con la finalidad de asegurar la prestación integral y adecuada en la totalidad del territorio provincial de los servicios de competencia municipal, hay que referirla, en el marco de una interpretación sistematizada, a aquellos servicios eminentemente transversales en el ámbito de la provincia, atribuidos a los municipios de forma homogénea y uniforme con el carácter de competencia propia y singularmente orientada hacia los servicios a que se refiere el art. 26 de la LRSAL, con el carácter de obligatorios para los municipios de menos de 20.000 habitantes.

39 Pues para DEL GUAYO (2014): 12 son servicios públicos locales la práctica totalidad de los servicios mencionados en el artículo 26 LRBRL.

$40 Y$ que VELASCO CABALLERO (2014): 3 considera que es consecuencia de una reacción centralizadora que pretende proceder a un reduccionismo de los Estatutos de Autonomía.

41 STC 103/2013, de 25 de abril, FJ. 5 c). 
En breve, el nuevo modelo competencial local surgido de la LRSAL se caracteriza por los siguientes aspectos fundamentales:

$1^{\circ}$. Distinción entre competencias propias y delegadas, por una parte y, por otra, en el Anteproyecto de LRSAL, competencias impropias, y en el texto definitivo de la LRSAL, tras las objeciones terminológicas expresadas por el Consejo de Estado, distintas de las propias y atribuidas por delegación ${ }^{42}$, artículos 7.1 y 7.4 LRBRL, respectivamente.

$2^{\circ}$. Orden de prelación en el ejercicio de las competencias. Sólo cabe el ejercicio de competencias, distintas de las propias y de la delegadas, cumpliendo las exigencias de sostenibilidad financiera sin incurrir en duplicidad, igualmente tras las salvedades del Consejo de Estado, en el ejercicio simultáneo del mismo servicio y se cuenta con un doble informe favorable; en el Anteproyecto, del interventor y de la Comunidad Autónoma y, en el texto definitivo de la ley, de la Comunidad Autónoma (administración competente por razón de la materia y titular de la tutela financiera) de carácter preceptivo y vinculante, artículo 7.4 LRBRL. Por tanto, la obligación primaria es el ejercicio de las competencias propias y delegadas y, de forma subsidiaria y bajo condiciones estrictas, de otras competencias.

$3^{\circ}$. Financiación. Para las materias enumeradas en el artículo 25.2 LRBRL los municipios cuentan con la participación en los ingresos del Estado; las atribuidas o delegadas por los legisladores sectoriales, sobre todo autonómicos, deben prever dotación económica y las competencias "impropias" afrontadas con los ingresos propios de los municipios.

$4^{\circ}$. No uniformidad del sistema competencial ${ }^{43}$. De forma expresa ${ }^{44}$ se excepciona para las Comunidades Autónomas de País Vasco y Navarra (artículo 2.4 y Disposición adicional $2^{\mathrm{a}} .2$ LRSAL, respectivamente), que éstas puedan, en el ámbito de sus competencias, "atribuir competencias como propias a los municipios en sus respectivos territorios con sujeción, en todo caso, a los criterios señalados en los apartados 3, 4 y 5 del artículo 25 ” de la LRBRL, lo que puede inducir a pensar que esta posibilidad queda vetada para el resto de las Comunidades Autónomas a partir de la entrada en vigor de la LRSAL; aunque algunas Comunidades Autónomas, como la de Castilla y León, ya ha manifestado su voluntad política en contrario, como luego veremos.

$5^{\circ}$. Indefinición temporal del traspaso de competencias municipales a las Comunidades Autónomas en los ámbitos de las Disposiciones transitorias $1^{\mathrm{a}}, 2^{\mathrm{a}}$ y $3^{\mathrm{a}}$, así como la Disposición adicional $15^{\mathrm{a}} \mathrm{LRSAL}$, las cuales establecen la asunción por las Comunidades Autónomas de competencias que antes venían siendo ejercidas por los municipios en materia de salud, servicios sociales y educación.

Situación competencial que ha generado un evidente recelo en las Comunidades Autónomas, así como evidentes expectativas en las entidades municipales, pues la asunción de estas competencias quedan condicionadas a la futura reforma de la Hacienda autonómica. De esta forma, la reacción normativa que ha existido en diversas Comunidades es regular el régimen jurídico de este conjunto de competencias. $\mathrm{Y}$ un buen ejemplo de ello es el Decreto-Ley 1/2014, de 27 de marzo aprobado por la Junta de Castilla y León ${ }^{45}$ en el cual se establece, en su Exposición de Motivos que:

“La sentencia del Tribunal Constitucional 214/1989, de 21 de diciembre, con cita de los principios de descentralización y máxima proximidad de la gestión administrativa a los ciudadanos, establece que «corresponde al legislador estatal la fijación de los principios básicos en orden a las competencias que deban reconocerse a las entidades locales (... fijando al respecto unas directrices para llevar a cabo tales competencias (... )». La citada sentencia expresa que la función constitucional encomendada al legislador estatal es la de garantizar los mínimos competenciales que dotan de contenido y efectividad la garantía de la autonomía local. No puede interpretarse que la recién aprobada reforma local del Estado haya invertido este modelo".

42 Tal y como se recoge en el apartado VI del Dictamen del Consejo de Estado $\mathrm{n}^{\circ} 567 / 2013$, de 26 de junio, al señalar este órgano consultivo que debía objetarse que se consagrara legalmente como expresión para denominar una categoría formal de competencias la de "competencias impropias", pues tratándose de un tertium genus distinto de las competencias propias y de las delegadas y, precisamente por ello y porque el Anteproyecto incorpora diversas normas sustantivas en relación con tales competencias, no parecía apropiado acudir a dicha expresión para referirse a ellas. Por el ello el Consejo de Estado sugirió asignarles otra denominación, la de “competencias distintas de las propias y de las delegadas", aspecto que fue incorporado en la redacción del artículo 7.4 LRBRL.

43 Pues el contenido de la Disposición Adicional $3^{\text {a }}$, que establece que "las disposiciones de esta Ley son de aplicación a todas las Comunidades Autónomas, sin perjuicio de sus competencias exclusivas en materia de régimen local asumidas en sus Estatutos de Autonomía, en el marco de la normativa básica estatal y con estricta sujeción a los principios de estabilidad presupuestaria, sostenibilidad financiera y racionalización de las estructuras administrativas", resulta de imposible aplicación en aquellas Comunidades Autónomas con un contenido distinto a la LRSAL, pues no puede armonizarse la aplicación simultánea de normas jurídicas contradictorias.

44 Y también podrían verse excepcionadas parcialmente, por aplicación de la Disposición Adicional $3^{\mathrm{a}}$.2, Cataluña; por la Disposición Adicional $3^{\mathrm{a}} \cdot 3$, Aragón; por la Disposición adicional 16a apartados 1 y 1, Canarias e Illes Baleares, respectivamente.

45 BOCYL n ${ }^{\circ}$ 62, de fecha 31 de marzo de 2014. 
Por lo que este Decreto-Ley establece, en su artículo 4.1, que:

"Las competencias que, con carácter previo a la entrada en vigor de la Ley 27/2013, de 27 de diciembre, de racionalización y sostenibilidad de la Administración Local, se preveían como propias de los municipios en materia de participación en la gestión de la atención primaria de la salud e inspección sanitaria, en materia de prestación de servicios sociales, y de promoción y reinserción social, así como aquellas otras en materia de educación, a las que se refieren las Disposiciones adicional decimoquinta y transitorias primera, segunda y tercera de la Ley 27/2013, de 27 de diciembre, de racionalización y sostenibilidad de la Administración Local, continuarán siendo ejercidas por los municipios en los términos previstos en las Leyes correspondientes, en tanto no hayan sido asumidas por parte de la Comunidad de Castilla y León".

\subsection{Las competencias locales en las reformas autonómicas}

Después de aprobada la LRSAL diversas Comunidades Autónomas han procedido a regular el ámbito competencial de las entidades locales, con un sentido distinto al marcado por la LRSAL, además de proceder, alguna de ellas, a su impugnación ante el Tribunal Constitucional ${ }^{46}$. En este sentido, las Comunidades Autónomas de Andalucía, Asturias ${ }^{47}$, Castilla León, Cataluña, Extremadura, Galicia, Illes Balears ${ }^{48}$, La Rioja ${ }^{49}$, Madrid y Murcia ${ }^{50}$, han regulado normativamente el régimen local en sus respectivos ámbitos territoriales para establecer un aparente "cortafuegos" normativo a la LRSAL.

En Madrid, la Ley autonómica 1/2014, de 25 de julio, justifica su aprobación por cuanto,

"las disposiciones de la citada Ley 27/2013, de 27 de diciembre, son de aplicación a todas las Comunidades Autónomas, sin perjuicio de sus competencias exclusivas en materia de régimen local asumidas en sus Estatutos de Autonomía. En el caso de la Comunidad de Madrid, las disposiciones de la ley suponen la asunción de nuevas funciones y competencias, tanto en el ejercicio de las propias como Comunidad Autónoma, como de las relativas a las Diputaciones Provinciales, y que debe ejercer dada su condición de Comunidad uniprovincial, lo que requiere, en todo caso, el adecuado y suficiente sistema de financiación".

Y en su artículo 3.2 se establece que ${ }^{51}$ :

"Las competencias atribuidas a los Municipios por leyes anteriores a la entrada en vigor de la Ley 27/2013, de 27 de diciembre, de Racionalización y Sostenibilidad de la Administración Local se ejercerán por los mismos de conformidad con las previsiones contenidas en la norma de atribución, en régimen de autonomía y bajo su propia responsabilidad, de acuerdo con el artículo 7.2 de la Ley 7/1985, de 2 de abril, reguladora de las Bases del Régimen Local, sin perjuicio de lo dispuesto en la presente ley".

Difiriendo la asunción de las competencias municipales en materia de salud, educación y servicios sociales, según dispone su disposición adicional 1 ${ }^{\mathrm{a}}$, al momento de aprobación de un nuevo sistema financiero autonómico:

"Las competencias relativas a la educación, previstas en la disposición adicional decimoquinta de la Ley $27 / 2013$, de 27 de diciembre, y las relativas a salud y servicios sociales establecidas en las disposiciones transitorias primera y segunda de la misma ley, continuarán siendo ejercidas por los Municipios en los términos previstos en las leyes de atribución y en los convenios de colaboración que, en su caso, estén vigentes, hasta que hayan sido asumidas por parte de la Comunidad de

46 En este sentido se han interpuesto, y admitidos, recursos de inconstitucionalidad por parte del Gobierno de Andalucía ( $n^{\circ} 1959 / 2014$ ), la Asamblea de Extremadura ( $n^{\circ}$ 1792/2014), el Gobierno de Asturias ( $n^{\circ}$ 1995/2014), el Parlamento de Cataluña (1996/2014), el Parlamento de Navarra ( $n^{\circ}$ 2001/2014), el Parlamento de Andalucía (2003/2014), el Gobierno de Cataluña ( $n^{\circ} 2006 / 2014$ ) y el Gobierno de Canarias ( $n^{\circ}$ 2043/2014); además también se ha interpuesto recurso de inconstitucionalidad por diversos diputados del Congreso ( $\left.{ }^{\circ} 2002 / 2014\right)$ y, por último, se ha admitido un conflicto de defensa de la autonomía local por un gran número de municipios españoles ( $n^{\circ} 4292 / 2014$ ). Además, el Tribunal Constitucional ha desestimado la solicitud de suspensión de algunos preceptos de la LRSAL planteada por el Parlamento de Cataluña como medida cautelar de su recurso de inconstitucionalidad; y, por último, se ha inadmitido el conflicto en defensa de la autonomía local contra la LRSAL planteado por el Consejo Insular de Formentera, por Auto de fecha 7 de octubre de 2014.

47 . Decreto 68/2014, de 10 de julio.

48 . Decreto-Ley 2/2014, de 21 de noviembre.

49 . Ley $2 / 2014$, de 3 de junio.

50 . A través de la Ley 6/2014, de 13 de octubre y previamente a través del Decreto-Ley 1/2014, de 27 de junio.

51 . En un sentido similar el artículo 1 de la Ley 6/2014 murciana y artículo 1 Decreto-Ley 2/2014 de Illes Balears. 
Madrid, mediante el establecimiento de un nuevo Sistema de Financiación Autonómica que permita su asunción".

En Cataluña, el Decreto-Ley 3/2014, de 17 de junio, justifica su aprobación en la inseguridad jurídica que está generando la LRSAL al señalar que:

"la entrada en vigor de la Ley 27/2013, de 27 de diciembre, el pasado 31 de diciembre de 2013, y los meses transcurridos desde entonces, en los que la incertidumbre jurídica ha generado la sucesión de numerosas y contradictorias interpretaciones por parte de los entes locales, han evidenciado la necesidad de disponer de una norma que ofrezca seguridad jurídica y garantías del mantenimiento de la autonomía local en los términos contemplados por el Estatuto de autonomía de Cataluña. La situación de indefinición generada está permitiendo que cada municipio haga una interpretación diferente, en cuanto a las materias competenciales sobre las que puede prestar servicios públicos a los ciudadanos, cuando tendrían que ser las mismas, para preservar el principio constitucional de igualdad (...). Este escenario de incertidumbre afecta al funcionamiento diario de los entes locales puesto que la Ley estatal es vigente" ${ }^{52}$.

Por ello, en su Disposición adicional primera establece que:

“Los entes locales de Cataluña seguirán ejerciendo las competencias propias atribuidas por el Estatuto de autonomía de Cataluña y por la legislación sectorial de Cataluña, vigentes a la entrada en vigor de la Ley 27/2013, de 27 de diciembre, de racionalización y sostenibilidad de la Administración local".

Y en la Disposición adicional cuarta establece que:

“Las competencias que, previamente a la entrada en vigor de la Ley 27/2013, de 27 de diciembre, de racionalización y sostenibilidad de la Administración local, estén atribuidas como propias de los entes locales por el Estatuto de autonomía de Cataluña y por las leyes sectoriales catalanas en materia de servicios sociales, enseñanza, salud e inspección sanitaria, así como las delegadas, continuarán siendo ejercidas en los mismos términos y condiciones", y en su apartado $2^{\circ}$ precisa que:

“Las competencias que, previamente a la entrada en vigor de la Ley 27/2013, de 27 de diciembre, de racionalización y sostenibilidad de la Administración local, no estén atribuidas como propias de los entes locales por el Estatuto de autonomía de Cataluña y por las leyes sectoriales catalanas en materia de servicios sociales, enseñanza, salud e inspección sanitaria, serán asumidas por la Generalidad de Cataluña en los términos que establezcan las normas reguladoras del sistema de financiación de las comunidades autónomas y de las haciendas locales. Mientras no entren en vigor las normas reguladoras del sistema de financiación mencionadas y no se cumplan los plazos previstos en las disposiciones transitorias primera, segunda y tercera de la Ley 27/2013, de 27 de diciembre, los entes locales continuarán ejerciendo estas competencias en los mismos términos y condiciones".

En Galicia, la exposición de motivos de la Ley autonómica 5/2014, de 27 de mayo, justifica su aprobación ante la ausencia de reglas legales que señalen con claridad el "régimen aplicable a las competencias (municipales) atribuidas en la legislación autonómica anterior a la entrada en vigor de la ley”, y considera que:

“Es evidente también que no pueden imponerse a las normas aprobadas con anterioridad a la entrada en vigor de la ley básica requisitos previstos en el artículo 25 que sólo son de aplicación a las aprobadas en el nuevo sistema vigente tras la reforma, como los de previsión de la dotación financiera, cuando las competencias propias de las entidades locales vienen sustentadas aún por el actual sistema de financiación".

Por lo que concluye, en su Disposición adicional primera, la continuación de su ejercicio en las condiciones establecidas con anterioridad a la Ley 27/2013, "sin perjuicio de lo dispuesto en las disposiciones adicionales cuarta y quinta sobre la asunción por la Comunidad Autónoma de las competencias relativas a la educación, salud y servicios sociales", las cuales "continuarán siendo prestadas por los municipios en tanto no se den las condiciones 
previstas para su traspaso en la normativa básica y, en particular, el establecimiento del nuevo sistema de financiación autonómica y de las haciendas locales previsto en la misma”, Disposición adicional 4.1.

En Andalucía, por su parte, se ha aprobado el Decreto-Ley 7/2014, de 20 de mayo, en el que se establece que:

"Las competencias atribuidas a las entidades locales de Andalucía por las leyes anteriores a la entrada en vigor de la Ley 27/2013, de 27 de diciembre, de Racionalización y Sostenibilidad de la Administración Local, se ejercerán por las mismas de conformidad a las previsiones contenidas en las normas de atribución, en régimen de autonomía y bajo su propia responsabilidad, de acuerdo con lo establecido en el artículo 7.2 de la Ley 7/1985, de 2 de abril, reguladora de las Bases del Régimen Local, todo ello sin perjuicio de lo dispuesto en los artículos siguientes del presente Decreto-ley".

Además, en materia de educación, salud y servicios sociales se establece en la Disposición Adicional Única de esta norma andaluza que ${ }^{53}$ :

"Las competencias que, con carácter previo a la entrada en vigor de la Ley 27/2013, de 27 de diciembre, se preveían como propias de los municipios en materia de participación en la gestión de la atención primaria de la salud e inspección sanitaria, en materia de prestación de servicios sociales, y de promoción y reinserción social, así como aquellas otras en materia de educación, a las que se refieren las disposiciones adicionales decimoquinta y transitorias primera, segunda y tercera de la Ley $27 / 2013$, de 27 de diciembre, continuarán siendo ejercidas por los municipios en los términos previstos en las leyes correspondientes, en tanto no hayan sido asumidas por parte de la Comunidad Autónoma (...)".

Y este conjunto de preceptos autonómicos resultan muy similares a los contenidos en el Real Decreto Ley $1 / 2014$, de 27 de marzo de Castilla y León, el cual ha supuesto la norma inicial de esta corriente legisladora autonómica. De esta forma, en esta norma se afirma que son competencias propias de los municipios las ya atribuidas a las entidades locales de Castilla y León "por las leyes de las Comunidades Autónomas anteriores a la entrada en vigor de la Ley $27 / 2013(. .$.$) ”, artículo 1^{\circ}$.

Incluso en esta Comunidad Autónoma se ha dictado una Circular, de fecha 1 de abril de 2014, en la que se afirma que la LRSAL "no prohíbe a las Comunidades Autónomas atribuir otras competencias a las entidades locales distintas de las previstas en los artículos 25.2 y 36.1, ni a éstas ejercerlas”, por lo que las leyes autonómicas que atribuyeron competencias a las entidades locales antes de la aprobación de la LRSAL “, no han perdido vigencia como consecuencia de la aprobación de esta norma", y con la cual esta atribución de competencias realizada por las Comunidades Autónomas "siguen plenamente vigentes y su ejercicio sigue estando sometido a aquellas normas de atribución sin necesidad de someterse a los informes del artículo 7.4 de la LRBRL". Y sólo para las competencias "distintas de las atribuidas por las leyes sectoriales -estatales o autonómicas- y de las atribuidas por delegación” cabe aplicar este artículo 7.4.

Y esta forma de operar a través del "soft law" ya había sido anticipada por la Comunidad Autónoma del País Vasco a través de la Circular de fecha 11 de marzo de 2014, en la cual se considera que la LRSAL "no puede desconocer o menoscabar las competencias correspondientes a la Comunidad Autónoma de Euskadi (...), competencias que emanan directamente de la Ley Orgánica 3/1979, de 18 de diciembre de Estatuto de Autonomía para el País Vasco". En este entendimiento de las competencias autonómicas, esta Circular establece que, en relación con las competencias que los municipios venían ejerciendo antes de la entrada en aplicación de la LRSAL, los municipios "seguirán ejerciendo dichas competencias en tanto no sean atribuidas por la legislación sectorial en vigor y exista financiación para ellas, con independencia de que se refieran o no a materias que figuren en el listado del artículo 25.2 LRBRL"; y en relación con las posibles nuevas competencias atribuidas por el legislador autonómico, tras la entrada en vigor de la LRSAL, esta Circular afirma que las instituciones autonómicas y forales "podrán atribuir a los municipios nuevas competencias como propias (...) en materias en las que dichas instituciones sean competentes , con independencia de si la materia sobre la que verse la competencia se encuentre o no en el listado del artículo 25.2 LRBRL", debiendo en este caso seguir el procedimiento establecido en los apartados 3, 45 del citado artículo 25 .

A nuestro entender la causa fundamental de esta voluntad de los legisladores autonómicos de oponerse a la línea argumental marcada por la LRSAL descansa, en el plano jurídico, en una incorrecta redacción del artículo 25.2

53 En un sentido similar se expresan los artículos 6 y 7 de la Ley murciana de fecha 13 de octubre de 2014, y el artículo 6.1 del Decreto-Ley 2/2014 de Illes Balears. 
LRBRL, que estas Comunidades Autónomas entienden que es un precepto de "mínimos" y el legislador estatal de la LRSAL entiende que es de "máximos", pues establecería un régimen competencial común para todos los municipios españoles.

A ello habría que añadir el reajuste competencial realizado por el Estado en las materias contenidas en las Disposiciones transitorias $1^{\mathrm{a}}, 2^{\mathrm{a}}$ y $3^{\mathrm{a}}$, así como la Disposición adicional $15^{\mathrm{a}} \mathrm{LRSAL^{54 }}$, que puede suponer una contradicción con las normas estatutarias y sectoriales vigentes en esta materia, y que ha conducido a varias Comunidades Autónomas a interponer recursos de inconstitucionalidad frente a estos preceptos y, mientras, han regulado en el sentido de diferir el ejercicio de estas competencias a una futura reforma del sistema autonómico de financiación. Lo que supone desplazar "sine die" la aplicación de estas disposiciones normativas.

Desde una dimensión política, la legislación autonómica dictada supone una confrontación evidente con la configuración del régimen local, en su dimensión competencial, contenida en la LRSAL, lo cual genera una evidente inseguridad jurídica tal y como se pone de manifiesto en el Decreto-Ley catalán 3/2014.

\subsection{Los problemas de aplicación del nuevo modelo competencial}

La comprensión completa de este problema competencial se alcanza si se analiza con cierto detalle el recorrido parlamentario seguido para la regulación de las competencias propias locales en la LRSAL.

Mientras que el Anteproyecto las limitaba con aparente claridad al listado de materias contenido en el artículo 25.2, el texto definitivo de la LRSAL ofrece la misma indefinición existente desde la primera redacción de la LRBRL, lo cual ahonda en el problema endémico de constituirse en causa de interpretaciones equívocas.

Así, en el Anteproyecto de la LRSAL la limitación del conjunto de las competencias propias municipales resultaba evidente, al disponer la Disposición transitoria novena que: "las competencias distintas de las previstas en los artículos 25.2 y 27 de la Ley $7 / 85$ Reguladora de las Bases de Régimen Local que hasta la entrada en vigor de esta Ley vinieran ejerciendo los municipios sólo podrán seguir ejerciéndolas si cumplen con lo previsto en el apartado 4 del artículo 7 de la Ley $7 / 85 "$.

De esta forma, extramuros de la enumeración contenida en el citado artículo 25.2 las competencias serían delegadas o impropias y el legislador autonómico no podría atribuir otras competencias propias distintas de las establecidas por el legislador estatal en la LRBRL.

Y así lo entendió el Consejo de Estado cuando afirmó que:

"Pasa de establecer un listado abierto de competencias susceptibles de ser legalmente reconocidas a los municipios y a enunciar tales competencias de forma exhaustiva y aparentemente cerrada. Ello determina que no quepa en el sistema que el Anteproyecto configura la atribución como competencias propias de otras distintas de las incluidas en dicha relación, lo que constituye una significativa diferencia con respecto al actual modelo de asignación de competencias, en el que cualquier ley sectorial puede reconocer al municipio como propias competencias para actuar en un determinado ámbito". Añadiendo además, que "si como consecuencia de tal operación se produce una alteración del marco normativo competencial de los municipios tal y como ha sido definido por las Comunidades Autónomas, habrán de ser éstas las que acomoden su legislación a lo dispuesto con carácter básico por el legislador estatal”55.

Pero este precepto no aparece en la redacción final de la LRSAL. En la tramitación parlamentaria de esta reforma, el Grupo Popular presentó una enmienda aprobada en Comisión en fecha 7 de noviembre de $2013^{56}$ que extendía las competencias propias municipales a las reconocidas por los legisladores autonómicos en materias distintas al listado del artículo 25. La propuesta añadía un apartado 6 al artículo 25 del siguiente tenor: "cuando por Ley, las Comunidades Autónomas en sus respectivos ámbitos competenciales atribuyan a los municipios

54 De cuya constitucionalidad duda VELASCO CABALLERO (2014): 7, pues supone que el Estado pueda suprimir competencias municipales en materias de titularidad autonómica. En este sentido señala que en materia de salud, el Estado dispone de, únicamente, una competencia básica, las «bases y coordinación general de la sanidad» (artículo 149.1.16 CE), por lo que algunas leyes autonómicas han atribuido concretas competencias sobre sanidad o salud pública a los municipios; desde esta perspectiva se puede afirmar que la competencia estatal básica (ex artículo 149.1.16 CE) no permite al Estado eliminar las competencias municipales sobre salud. Y en lo que se refiere a la asistencia social ("servicios sociales», según el artículo 25.2.k LRBRL vigente hasta la reforma de la LRSAL) el Estado carece de toda competencia expresa, pues la asistencia social es una competencia atribuida en exclusiva por todos los Estatutos de autonomía a las respectivas Comunidades Autónomas.

55 Dictamen 567/2013, de fecha 26 de junio, Consideración VI.

56 BOCG-Senado $\mathrm{n}^{\circ} 260$, de fecha 7 de noviembre. 
competencias propias en materias distintas a las previstas en el apartado 2 del presente artículo, deberán tener en cuenta los criterios señalados en los apartados 3, 4 y 5 anteriores".

Paradójicamente la FEMP solicitó la supresión de la enmienda porque temía la proliferación de este tipo de competencias sin financiación adicional, por eso su posición fue la de considerar que,

“este párrafo modifica el eje central de la Ley en cuanto al sistema de atribución de competencias, ya que deja la puerta abierta a que las Comunidades Autónomas puedan atribuir como propias a las entidades locales distintas de las referidas en el artículo 25.2 (... ). La introducción de este apartado 6 supone dar carta de naturaleza, nuevamente en el régimen local, a las competencias impropias. Permitiría que los municipios tuvieran que atender competencias autonómicas que las Comunidades Autónomas les encomendaran, y además sin financiación paro ello, sin un lazo mínimo y sin la garantía regulada en esta Ley" 57 .

Ante la supresión de este apartado 6 del artículo 258 , así como de la Disposición transitoria novena del Anteproyecto, cobra especial relevancia jurídica la expresión “en todo caso" contenida en el artículo 25.2 LRBRL y la enumeración, entonces, reviste la consideración de un mínimo ampliable por los legisladores autonómicos ${ }^{59}$.

Sin embargo, el Consejo de Estado sigue afirmando la interpretación sostenida en el Dictamen emitido en relación con el Anteproyecto de la LRSAL. En este sentido, y con motivo de una solicitud planteada por el Alcalde de Barcelona, este Consejo reproduce la argumentación del citado Dictamen y alude a la suprimida enmienda del artículo 25 sobre la inclusión del mencionado apartado 6 para concluir que el listado del artículo 25.2 reviste el carácter de una enumeración exhaustiva y cerrada, un numerus clausus que circunscribe, al listado del artículo 25.2, la legislación autonómica para la atribución de competencias propias a los municipios. En ese Dictamen se afirma que:

“La LRSAL ha modificado el artículo 25.2 LRBRL con el objeto de que los municipios sólo pueden ejercer competencias sobre las materias mencionadas en dicho precepto, de forma que el ejercicio de competencias municipales sobre cualesquiera otras materias deberá atribuirse necesariamente por delegación del Estado o de las Comunidades Autónomas de conformidad con el artículo 27 LRBRL, o sujetarse a los requisitos específicos de las competencias distintas de las propias o de las atribuidas por delegación, establecidos en el artículo 7.4 LRBRL" ${ }^{60}$.

Y esta interpretación parece chocar con la línea interpretativa sostenida por el Tribunal Constitucional, y que queda patente en la sentencia dictada en relación con el Estatuto catalán en la cual se afirma que, en virtud de la competencia estatal en materia de bases del régimen local contenida en el artículo 149.1.18 CE:

"Corresponde al legislador estatal fijar «unos principios o bases relativos a los aspectos institucionales (organizativos y funcionales) y a las competencias locales» de los entes locales constitucionalmente necesarios (STC 214/1989, de 21 de diciembre, FFJ 1 y 4). En otras palabras, el elenco competencial que el precepto estatutario dispone que tiene que corresponder a los gobiernos locales en modo alguno sustituye ni desplaza, sino que, en su caso, se superpone, a los principios o bases que dicte el Estado sobre las competencias locales en el ejercicio de la competencia constitucionalmente reservada por el artículo 149.1.18 CE"'61.

La disputa competencial resulta así evidente. Mientras las Comunidades Autónomas niegan la aplicación de la LRSAL a las competencias municipales concretadas en leyes anteriores a la aprobación de la LRSAL, a la vez que plantean su oposición a que el artículo 25.2 LRBRL tenga un carácter de cláusula de "máximos", el Estado realiza una interpretación diversa, por lo que ha planteado los conflictos de competencias ya señalados, lo que conduce a una situación de absoluta inseguridad jurídica para las entidades locales.

Por otra parte, en el ámbito de las competencias provinciales, la disputa se centra en la interpretación del artículo 26.2 LRBRL que determina la regula de las competencias municipales, y el ente prestador de éstas, en los municipios de población inferior a los 20.000 habitantes y en las materias de "recogida y tratamiento de residuos,

$57 \operatorname{FEMP}(2013): 4$.

58 Lo cual se produjo a través de la enmienda de supresión nº 421 del Grupo Parlamentario Popular, BOCG-Senado $n^{\circ} 276$ de 28 de noviembre de 2013.

59 Igualmente NAVARRO y ZAFRA (2014):4.

60 Dictamen 338/2014, de 26 de mayo, Consideración V.

61 Cit., FJ. 37. 
abastecimiento de agua potable a domicilio y evacuación y tratamiento de aguas residuales, limpieza viaria, acceso a los núcleos de población, pavimentación de vías urbanas y alumbrado público".

$Y$ es que, este precepto establece que será la entidad provincial, o "entidad equivalente", quien coordine la prestación de estos servicios y proponga al Ministerio de Economía y Administraciones Públicas su forma de prestación, "con la conformidad de los municipios afectados"; y sólo, si el municipio justifica "que puede prestar estos servicios con un coste efectivo menor" que el propuesto por la Diputación, aquél podrá asumir la prestación y coordinación de estos servicios.

Nos encontramos aquí ante el núcleo gordiano de la justificación misma de las entidades municipales, pues estos servicios se refieren al conjunto mínimo de servicios públicos de competencia municipal, pues según los datos puestos de manifiesto por el Consejo de Estado, esta situación puede afectar a casi el $97 \%$ de los municipios españoles ${ }^{62}$, por lo que induce a este Consejo que esta regulación puede resultar inconstitucional ${ }^{63}$.

Para acabar, la situación generada por la LRSAL, más allá de constituir o no una limitación legal de la autonomía local, deja una vez más en evidencia la fragilidad de la situación de las entidades locales en el marco constitucional. Esto es, se pone de manifiesto que la autonomía local, entendida en su dimensión de garantía institucional, no garantiza sino la mera preservación de las institucionales locales, pero resulta ineficaz para diseñar un ámbito competencial y económico que las permita actuar en el siglo XXI.

Nuestra apuesta camina por el concepto de "interés respectivo", del cual se ha obtenido una escasa rentabilidad interpretativa en nuestro Derecho. Quizás sea el momento de dirigir esta situación por esa vía.

\section{CONCLUSIONES}

En definitiva, se puede efectuar la siguiente propuesta de explicación (balance) de la situación competencial de las entidades locales:

$1^{\circ}$. La CE, que ha supuesto una inflexión en la situación (anclaje) de las entidades locales en relación con el Estado, caracteriza a éstas como entes dotados de autonomía para la gestión de sus respectivos intereses. De tal forma que deberán ser las leyes, estatales y autonómicas, los instrumentos a través de los cuales se deban especificar y graduar las competencias locales, teniendo en cuenta la relación entre intereses locales y supralocales en los asuntos que conciernen a la comunidad local y sin más límite que el reducto indisponible o núcleo esencial de la institución que la CE garantiza.

$2^{\circ}$. Este modelo constitucional ha sido escasamente desarrollado a nivel estatutario, pues la mayoría de los Estatutos de Autonomía difieren la resolución de este problema al ámbito del legislador sectorial.

$3^{\circ}$. Ante esta situación constitucional y estatutaria, y a la vista de la redacción originaria de la LRBRL, se produjo una actuación de las entidades locales autohabilitándose espacios competenciales realmente heterogéneos a través de la fórmula de las competencias complementarias.

$4^{\circ}$. La LRSAL ha tratado, sin conseguirlo de forma pacífica, de concretar el ámbito competencial de las entidades locales, pues diversas Comunidades Autónomas se han apresurado a regular, en el ejercicio de sus competencias propias, con la finalidad de mantener el "status quo" competencial anterior a la LRSAL.

Alguien podría sugerir, a la vista de todo ello, que "para este viaje no hacían falta alforjas"; pero lo que resulta evidente es que se ha desaprovechado una magnífica oportunidad para clarificar el modelo competencial de las entidades locales, el cual queda ahora en una zona conflictual a la espera de la respuesta del Tribunal Constitucional.

\section{BIBLIOGRAFÍA}

ALBI, F. (1996), La crisis del municipalismo, Madrid, Instituto de Administración Pública.

AUTEXIER, CH. (1981), "L’ancrage constitutionnel des collectivités locales”, Revue de Droit Public, nº 3.

\section{BELLO PAREDES, S. A.}

- (2002), Las Ordenanzas locales en el vigente Derecho español. Alcance y articulación con la normativa estatal y autonómica. Madrid, INAP.

62 Tal y como se reitera en su Dictamen de fecha 26 de mayo de 2014, cit.

63 Al constituir un supuesto de posible "supresión de contenidos fundamentales de la autonomía local con base en el incumplimiento de un parámetro económico -y único- configurado como elemento del que depende la continuidad de la prestación de servicios por parte del municipio puede afectar negativamente al núcleo esencial de la garantía institucional”, Dictamen de fecha 26 de junio de 2013 , cit., y reiterado por el de fecha 26 de mayo de 2014. 
- (2006), "La cooperación económica”, Revista Jurídica de Castilla y León, núm. extraordinario Pacto Local, págs. 245-260.

- (2010), "La situación de las Entidades locales en los Estatutos de Autonomía reformados: especial referencia al marco estatutario de Castilla y León”, Revista Jurídica de Castilla y León, 20, págs. 345-380.

CARRILLO DONAIRE, J.A. y NAVARRO RODRÍGUEZ, P. (2014), (Coordinadores), La reforma del régimen jurídico de la Administración Local. El nuevo marco regulatorio a la luz de la Ley de racionalización y sostenibilidad de la Administración Local, Las Rozas: El Consultor de los Ayuntamientos (La Ley).

DELPÉRÉE, F. (1981), "Les compétences du pouvoir local en Belgique”, en La décentralisation en Europe", París, CNRS.

FEDERACIÓN ESPAÑOLA DE MUNICIPIOS Y PROVINCIAS (2013), Propuesta de Enmiendas que presenta la FEMP al texto remitido al Senado del Proyecto de Ley de Racionalización y Sostenibilidad de la Administración Local".

GUAYO CASTIELLA, I. DEL (2014), "Nuevo régimen jurídico de los servicios públicos locales, tras la Ley núm. 27/2013, de 27 de diciembre, de racionalización y sostenibilidad de la Administración Local.

NAVARRO RODRÍGUEZ P. y ZAFRA VÍ́cTOR. M.,(2014), "El pretendido blindaje autonómico de las competencias municipales tras la reforma de la Administración Local”, REALA, $n^{\circ} 2$.

PAREJO ALFONSO, L.

- (1981), Garantía institucional y autonomías locales, Madrid, IEAL.

- (2009), “Autonomía Local, Régimen Local Básico y Reformas Estatutarias”, REALA, n 309, págs. 7-57.

REVISTA DE ESTUDIOS LOCALES, CUNAL, (2014): Extraordinario dedicado a: Análisis de la Ley 27/2013, de Racionalización y Sostenibilidad de la Administración Local, nº 169.

RIVERO YSERN, J.L. (2014), “Capítulo I. La crisis económica y la reforma del régimen jurídico de la Administración local” en CARRILLO DONAIRE, J.A. y NAVARRO RODRÍGUEZ, P. (2014), (Coordinadores), La reforma del régimen jurídico de la Administración Local. El nuevo marco regulatorio a la luz de la Ley de racionalización y sostenibilidad de la Administración Local, Las Rozas, El Consultor de los Ayuntamientos (La Ley).

ROMANO, S. (1964), Fragmentos de un Diccionario Jurídico, voz “Autonomía”, Ejea, Buenos Aires, págs. 38-44.

VELASCO CABALLERO, F. (2014) "El nuevo régimen local general y su aplicación diferenciada en las distintas Comunidades Autónomas”. Revista catalana de dret públic, nº 48 (2014), págs. 1-23. 
